\title{
Second malignancies after radiotherapy for prostate cancer: systematic review and meta-analysis
}

\author{
Christopher I D Wallis, ${ }^{1,2}$ Alyson L Mahar, ${ }^{1}$ Richard Choo, ${ }^{3}$ Sender Herschorn, ${ }^{1}$ Ronald T Kodama, ${ }^{1}$ \\ Prakesh S Shah, ${ }^{2,4}$ Cyril Danjoux, ${ }^{5}$ Steven A Narod, ${ }^{6}$ Robert K Nam ${ }^{1}$
}

'Division of Urology,

Sunnybrook Health Sciences

Centre, Sunnybrook Research

Institute, University of Toronto,

Room MG-406, 2075 Bayview

Avenue, Toronto, ON M4N 3M5,

Canada

IInstitute of Health Policy,

Management and Evaluation,

University of Toronto, Suite 425,

155 College Street, Toronto, ON

M5T 3M6, Canada

3Department of Radiation

Oncology, Mayo Clinic, 200 1st

Street Southwest, Rochester,

MN 55902, USA

4Department of Pediatrics,

Mount Sinai Hospital, University

of Toronto, 600 University

Avenue, Toronto, ON M5G 1X5,

Canada

5Department of Radiation

Oncology, Sunnybrook Health

Sciences Centre, Sunnybrook

Research Institute, University of

Toronto, Room MG-406, 2075

Bayview Avenue, Toronto, ON

M4N 3M5, Canada

${ }^{6}$ Department of Public Health

Sciences, University of Toronto,

7th floor, 790 Bay Street,

Toronto, ON M5G 1N8, Canada

Correspondence to: R Nam

Robert.nam@utoronto.ca

Additional material is published

online only. To view please visit

the journal online.

Cite this as: BMJ 2016;352:i851

http://dx.doi.org/10.1136/bmj.i851

Accepted: 20 January 2016

\section{ABSTRACT}

OBJECTIVE

To determine the association between exposure to radiotherapy for the treatment of prostate cancer and subsequent second malignancies (second primary cancers).

DESIGN

Systematic review and meta-analysis of observational studies.

\section{DATA SOURCES}

Medline and Embase up to 6 April 2015 with no restrictions on year or language.

\section{STUDY SELECTION}

Comparative studies assessing the risk of second malignancies in patients exposed or unexposed to radiotherapy in the course of treatment for prostate cancer were selected by two reviewers independently with any disagreement resolved by consensus.

\section{DATA EXTRACTION AND SYNTHESIS}

Two reviewers independently extracted study characteristics and outcomes. Risk of bias was assessed with the Newcastle-Ottawa scale. Outcomes were synthesized with random effects models and Mantel-Haenszel weighting. Unadjusted odds ratios and multivariable adjusted hazard ratios, when available, were pooled.

\section{MAIN OUTCOME MEASURES}

Second cancers of the bladder, colorectal tract, rectum, lung, and hematologic system.

\section{RESULTS}

Of 3056 references retrieved, 21 studies were selected for analysis. Most included studies were large multi-institutional reports but had moderate risk of bias. The most common type of radiotherapy was external beam; 13 studies used patients treated with surgery as controls and eight used patients who did not undergo radiotherapy as controls. The length of follow-up among studies varied. There was increased

\section{WHAT IS ALREADY KNOWN ON THIS TOPIC}

Management of prostate cancer has been fraught with concerns regarding overtreatment because of the considerable complications related to the treatment Secondary malignancies related to treatment represent perhaps the most serious of all complications

A previous meta-analysis of this subject lacked important recent publications

\section{WHAT THIS STUDY ADDS}

There is a possible association between radiotherapy for the treatment of prostate cancer and an increased risk of bladder, colorectal, and rectal cancers

These findings were consistent after adjustment for baseline patient and tumor factors as well as lag time restrictions risk of cancers of the bladder (four studies; adjusted hazard ratio $1.67,95 \%$ confidence interval 1.55 to 1.80 ), colorectum (three studies; $1.79,1.34$ to 2.38 ), and rectum (three studies; $1.79,1.34$ to 2.38 ), but not cancers of the hematologic system (one study; 1.64 , 0.90 to 2.99 ) or lung (two studies; $1.45,0.70$ to 3.01), after radiotherapy compared with the risk in those unexposed to radiotherapy. The odds of a second cancer varied depending on type of radiotherapy: treatment with external beam radiotherapy was consistently associated with increased odds while brachytherapy was not. Among the patients who underwent radiotherapy, from individual studies, the highest absolute rates reported for bladder, colorectal, and rectal cancers were $3.8 \%, 4.2 \%$, and $1.2 \%$, respectively, while the lowest reported rates were $0.1 \%, 0.3 \%$, and $0.3 \%$.

\section{CONCLUSION}

Radiotherapy for prostate cancer was associated with higher risks of developing second malignancies of the bladder, colon, and rectum compared with patients unexposed to radiotherapy, but the reported absolute rates were low. Further studies with longer follow-up are required to confirm these findings.

\section{Introduction}

Treatment options for patients with a diagnosis with clinically localized prostate cancer can include surgery or radiotherapy. ${ }^{1}$ Each option is associated with side effects including urinary incontinence and erectile dysfunction. ${ }^{23}$ Recently, other complications related to treatment and resulting in hospital admissions, genitourinary and recto-anal procedures, and major surgeries have been described.4-6 $\mathrm{A}$ unique complication for patients undergoing radiotherapy is the possibility of development of a secondary malignancy (second primary cancer).

Studies assessing the risk of secondary cancers after radiotherapy for prostate cancer have reported either an increased risk of secondary malignancies ${ }^{78}$ or no association between radiotherapy and secondary malignancies. ${ }^{910}$ One previous review concluded a negligible risk of secondary malignancies after radiotherapy, ${ }^{11}$ whereas other reviews concluded that this is an important risk for both patients and physicians to consider. ${ }^{12-14}$ A previous meta-analysis lacked data from several important recent publications. ${ }^{15}$

While direct radiation carcinogenesis has long been accepted, ${ }^{16}$ there is evidence that irradiation of the prostate might contribute to carcinogenesis outside the irradiated area through radiation scatter and radiation induced genetic alterations without direct exposure because of increased reactive oxygen species $^{17-19}$ and 
changes in gene expression in what has been termed the "bystander effect." ${ }^{20}$ We therefore carried out a systematic review and meta-analysis of available data on the association between radiotherapy and the development of secondary malignancies of the bladder, colorectal tract, lung, and hematological system in patients with prostate cancer compared with other treatments.

\begin{abstract}
Methods
Participants and exposure

We reviewed studies reporting on patients with confirmed adenocarcinoma of the prostate treated with commonly used forms of radiotherapy including conformal external beam, intensity modulated, brachytherapy, or a combination of types. We included studies irrespective of dose and duration of radiotherapy. Controls were patients who did not undergo radiotherapy, including those who were treated with surgery, other treatments for prostate cancer, or received no treatment. We conducted a subgroup analysis using only controls treated with surgery. When the comparator group was unclear, we excluded the study.
\end{abstract}

\section{Outcome}

Our primary outcome was the development of one or more histologically unique secondary cancers of the bladder, colorectal tract, rectum, lung, and hematologic system, excluding metastatic tumors. Studies reporting on rectal cancer were included in the analysis of colorectal cancer as well as in the analysis of rectal cancer.

It is argued that time (lag period) must elapse between the date of exposure to radiation and the development of a secondary cancer for that tumor to be considered induced by radiation..$^{13}$ Historically, this has been defined as five years. ${ }^{1321-23}$ There were differences in the use and application of the length of the lag period

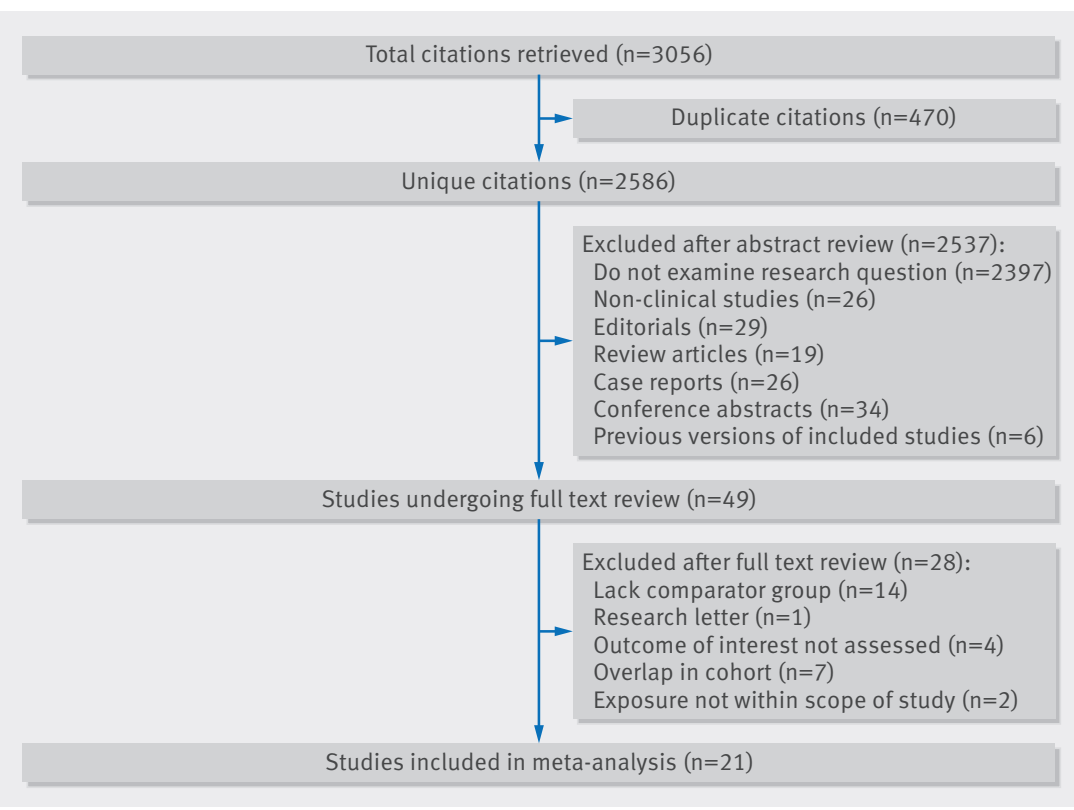

Fig 1 | Search strategy and final included and excluded studies of secondary malignancies after radiotherapy for prostate cancer from the time of treatment to diagnosis of secondary cancer among included studies. To deal with differences in how studies handled the lag period, we conducted separate analyses stratified by inclusion without respect to lag period to only those using a five year lag period and to only those using a 10 year lag period.

\section{Types of studies}

We included cohort and case control studies. We excluded case series that lacked comparator patients who did not undergo radiotherapy. Other publications on the topic, including basic science papers, review articles, editorials, articles not dealing with radiation induced malignancy, conference abstracts, early versions of data later published, and non-standard treatment (such as cryotherapy) were excluded (fig 1). When there was more than one publication resulting from the same cohort of patients, to prevent the duplication of patients from one cohort, for each of our analyses we selected one study based on a hierarchical assessment of comparability of study groups, definition of radiation exposure, time period of study (preference for more recent), and number of patients (appendix 1).

\section{Methods of review}

We used Preferred Reporting Items for Systematic Reviews and Meta-Analyses (PRISMA) and Meta-analysis of Observational studies in Epidemiology (MOOSE) guidelines for reporting of this systematic review and meta-analysis. ${ }^{24} 25$

\section{Search strategy}

With the help of a professional librarian we searched Medline and Embase databases using the OvidSP search platform for studies indexed up to 6 April 2015. Appendix 2 shows the detailed search strategy for each database. References from review articles, editorials, and included studies were reviewed and cross referenced to ensure completeness. Studies in any language were included. Conference abstracts were excluded.

\section{Selection and data extraction}

Two authors (CJDW and ALM) performed study selection. Titles and abstracts were screened for initial study inclusion, with full text review when the abstract was insufficient to determine if the study met the inclusion or exclusion criteria. Final agreement on study inclusion was made by discussion and consensus with other authors. Two reviewers performed all data extraction including evaluation of study characteristics, risk of bias, and outcome measures. Key variables were selected based on clinical and methodological relevance. Two authors pilot tested the data abstraction form to ensure completeness. Discrepancies were resolved through consensus (with PSS and RKN). Study authors were contacted when suitable data were not available.

\section{Assessment of risk of bias}

We used the Newcastle-Ottawa scale to assess risk of bias. This scale assesses risk in three domains: ${ }^{26}$ selection of 
the study groups, comparability of groups, and ascertainment of exposure and outcome. ${ }^{27}$ Studies that scored $>7$ were considered as having low risk of bias, scores of 5-7 indicated moderate risk of bias, and scores of $<5$ indicated high risk of bias.

\section{Statistical analysis}

Meta-analysis was performed with Review Manager 5.3 (Nordic Cochrane Centre, Cochrane Collaboration, 2014) software. We assessed the adjusted hazard ratio and unadjusted odds ratio of developing a secondary malignancy between participants treated with radiotherapy and controls. We first analyzed studies including any form of radiotherapy, stratified by studies that used controls groups comprising patients who did not undergo radiotherapy and patients treated with surgery.

Because of the clinical heterogeneity inherent in our data, we used random effects models for all meta-analyses. Given the relatively rare nature of our events, we used Mantel-Haenszel weighting. ${ }^{28}$ For adjusted hazard ratios, we used the inverse variance technique. Statistical heterogeneity was assessed with $\mathrm{I}^{2}$ values. ${ }^{29}$

As a post hoc analysis, we assessed the absolute risk difference between patients treated with radiotherapy and controls. We expressed this as the difference per 100 patients.

Subgroup analysis and exploration of heterogeneity We performed a priori subgroup analyses by examining studies that used only external beam radiotherapy and those that used only brachytherapy. For each of these analyses, we stratified by control group (no radiation and surgery). To further explore heterogeneity, we conducted meta-regression using the Newcastle-Ottawa risk of bias score as a continuous variable in random effects models for all comparisons comprising five or more studies.

\section{Patient involvement}

No patients were involved in setting the research question or the outcome measures, nor were they involved in the design and implementation of the study. There are no plans to involve patients in the dissemination of results.

\section{Results}

We retrieved 3056 references from our literature search (fig 1). After full text review of 49 manuscripts, we selected 21 reports for inclusion (table 1). Twenty eight studies were excluded; figure 1 lists the reasons. Of note, we identified 24 reports derived from the United States Surveillance, Epidemiology, and End Results (SEER) cohort in our literature search. These studies overlapped in their inclusion criteria, study intervals, patient selection, and outcome measures. To prevent the duplication of patients from the SEER cohort, we selected a single study to represent the SEER cohort for each comparison as outlined in appendix 1 . The studies used in each of the analyses are outlined in appendix 3.
We obtained unpublished data from the principal author of one study we included..$^{30}$ In a second case, we were unable to obtain necessary information for inclusion in a subgroup analysis, but the published data were adequate for our primary analysis. ${ }^{31}$

\section{Study description}

Table 1 shows characteristics of included studies. Eighteen were large multi-institutional reports, and three were single centre studies. ${ }^{103233}$ Conformal external beam radiotherapy was the most commonly assessed type of radiotherapy. There were insufficient data to distinguish between two dimensional, three dimensional, and intensity modulated radiotherapy, though most included studies assessed three dimensional conformal external beam radiotherapy. There were considerable differences in the definition and use of a lag period before outcome ascertainment (table 1). Length of follow-up also varied significantly between included studies (table 1). Thirteen studies (62\%) included patients treated with surgery as the comparator, and eight studies (38\%) used "no radiation" or "no radiation and no surgery" control groups (table 1). Crude incidence of individual secondary cancers ranged from $0.2 \%$ to $2.3 \%$ for patients treated with external beam radiotherapy, $0.1 \%$ to $2.1 \%$ for patients treated with brachytherapy, $0.2 \%$ to $1.7 \%$ for patients treated with brachytherapy and external beam boost, and $0.3 \%$ to $2.3 \%$ for patients not exposed to radiotherapy; however, these rates varied significantly between studies (table 1). Most studies did not specify whether the reported bladder cancers were superficial or invasive. For studies reporting adjusted hazard ratios, covariates included in the model varied significantly between studies though all included age at diagnosis (table A, appendix 4).

\section{Assessment of risk of bias}

Most studies were deemed to be of moderate risk of bias (table B, appendix 4). Commonly identified concerns include a lack of explicit demonstration that the outcome was not present at the start of the study, the length of follow-up, and attrition bias.

\section{Bladder cancer}

On unadjusted analysis with no restriction to lag period, we found an increased odds of bladder cancer (nine studies, 555873 participants; unadjusted odds ratio $1.39,95 \%$ confidence interval 1.12 to $1.71 ; \mathrm{I}^{2}=56 \%$; fig 2). The results were similar when we restricted analysis to studies with a five year lag period (three studies, 397416 participants; $1.30,1.19$ to 1.42 ; $\mathrm{I}^{2}=0 \%$; table 2 , fig 2) or a 10 year lag period (two studies, 99362 patients; $1.89,1.65$ to 2.16 ; $\mathrm{I}^{2}=0 \%$ ). After multivariable adjustment, we found an increased risk for bladder cancer in those treated with radiotherapy (four studies; adjusted hazard ratio 1.67, 95\% confidence interval 1.55 to $1.80 ; \mathrm{I}^{2}=0 \%$; fig 3 ). Absolute differences in risk of bladder cancer between patients exposed and unexposed to radiotherapy ranged from 0 to 0.6 cancers per 100 patients, depending on type of radiotherapy, comparator group, and lag period (table C, appendix 4). 


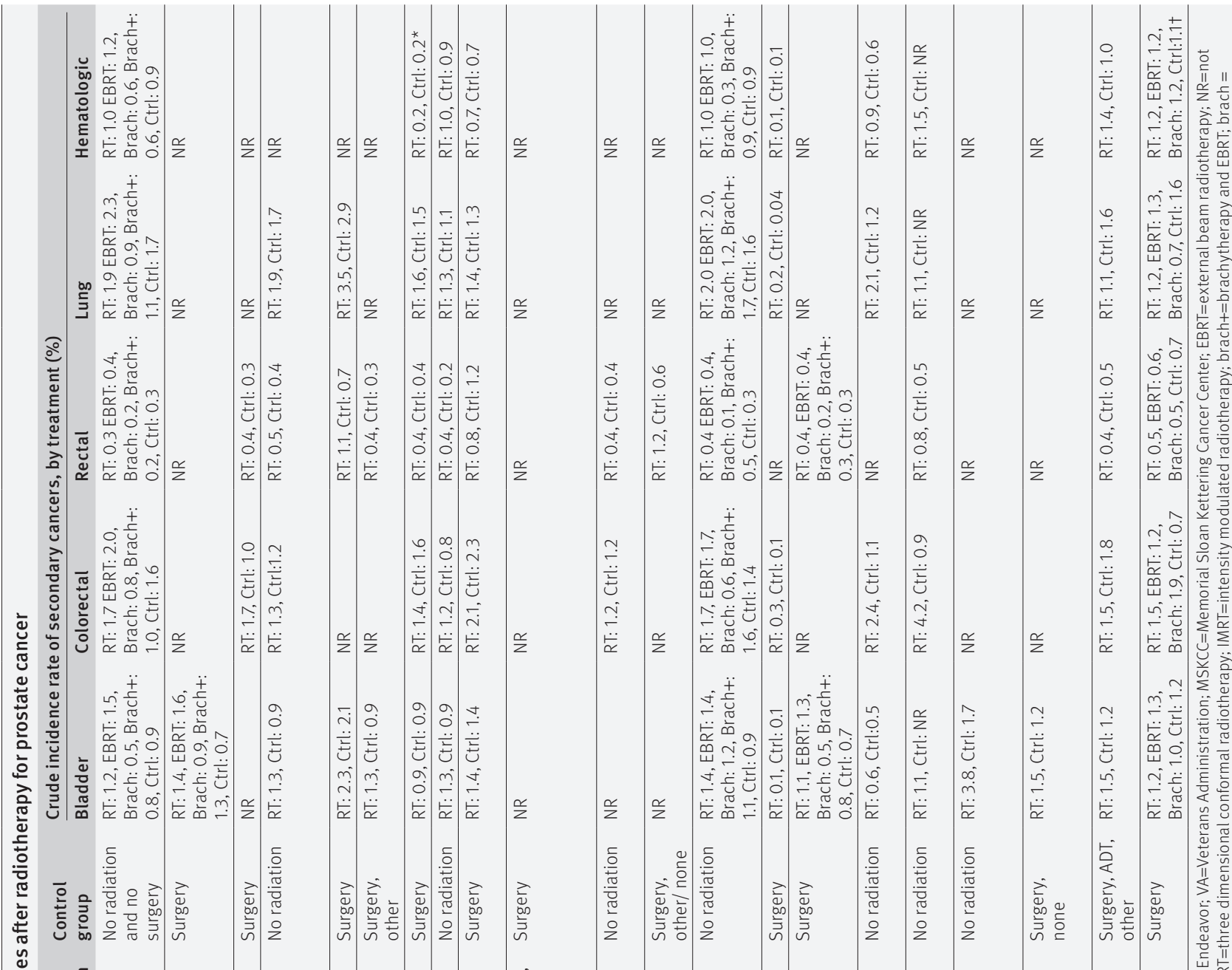

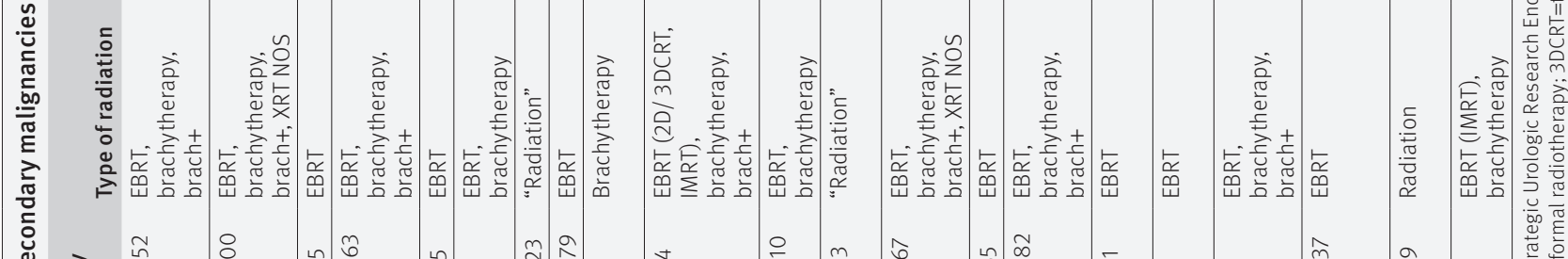

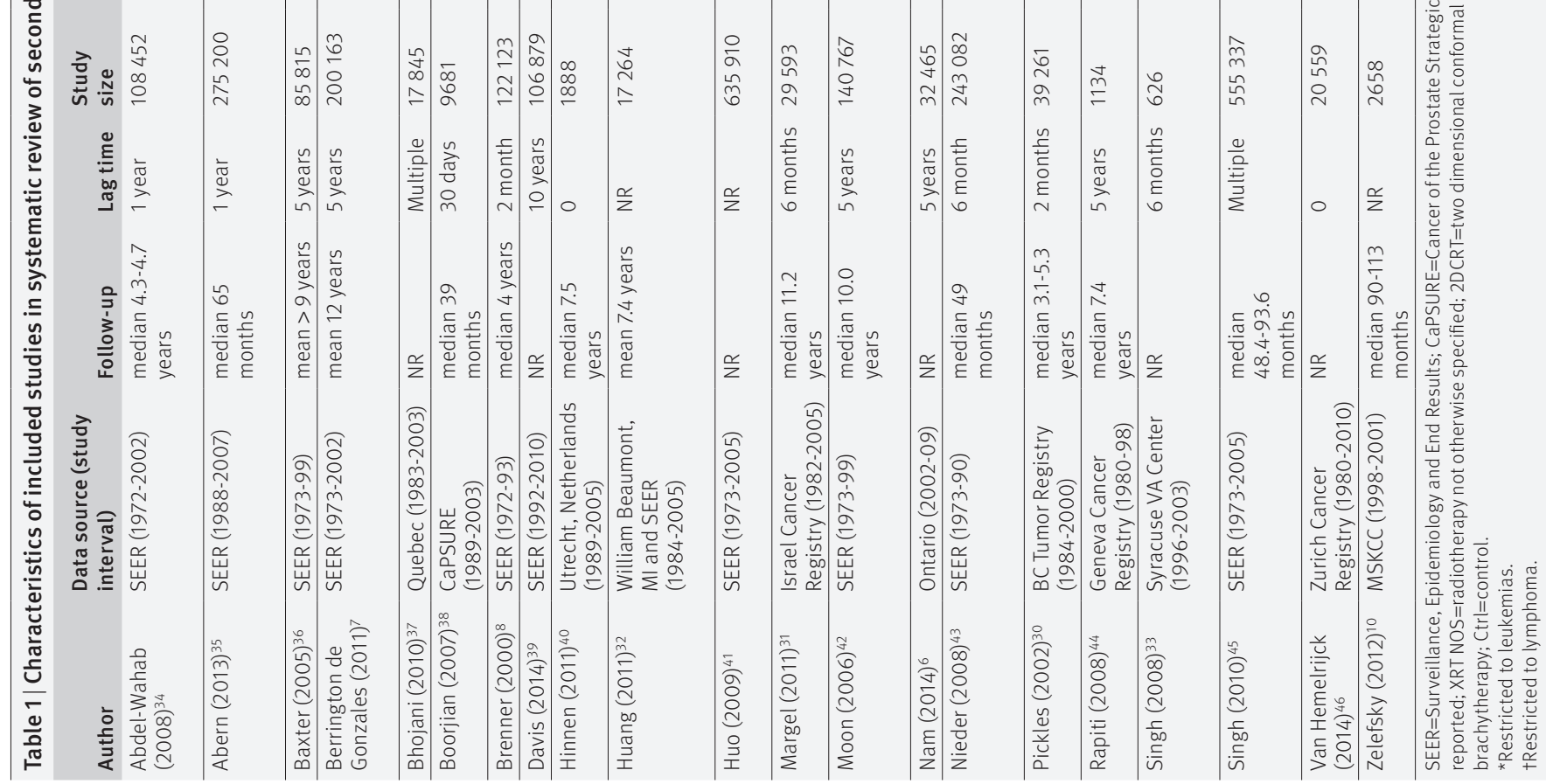




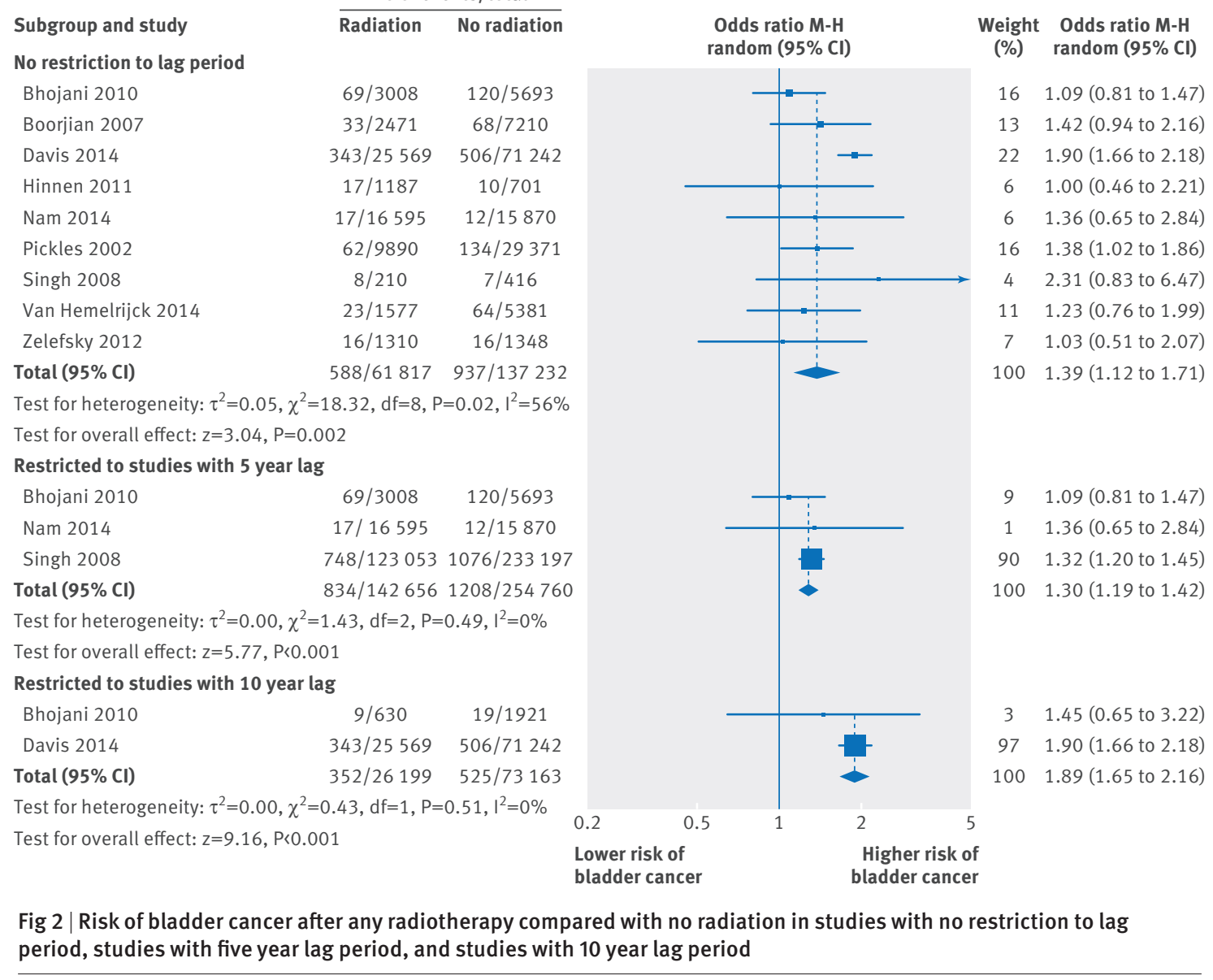

\section{Colorectal cancer}

On unadjusted analysis with no lag period, we found an increased odds of colorectal cancers after any form of radiotherapy compared with no radiation (10 studies; 228965 participants; unadjusted odds ratio 1.68, 95\% confidence interval 1.33 to 2.12 ; $\mathrm{I}^{2}=72 \%$; fig 4). Again, results were similar after we restricted analysis to studies with a five year lag period (four studies, 242878 patients; $1.94,1.07$ to $3.50, \mathrm{I}^{2}=86 \%$; table 2, fig 4) or a 10 year lag period (two studies, 99578 patients; $1.56,1.36$ to $1.80 ; \mathrm{I}^{2}=0 \%$ ). Pooled multivariable adjusted hazard ratios showed an increased risk for colorectal cancer in those treated with radiotherapy (three studies; adjusted hazard ratio 1.79 , 95\% confidence interval 1.34 to 2.38 ; $\mathrm{I}^{2}=28 \%$; fig 3 ). The absolute difference in colorectal cancers ranged from 0.2 to 1.4 cases per 100 patients for those treated with radiotherapy and controls, depending on type of radiotherapy, comparator, and lag period (table $\mathrm{C}$, appendix 4).

\section{Rectal cancer}

When we restricted analysis to cases of rectal cancer after radiotherapy, we identified an increased odds associated with radiotherapy in unadjusted analysis without restriction to lag period (eight studies, 157239 participants; unadjusted odds ratio 1.62, 95\% confidence interval 1.26 to 2.08 ; $I^{2}=33 \%$; fig 5). Restriction of analysis to those studies with a five year lag period showed no significant association (three studies, 204064 patients; $1.68,0.90$ to $3.15, \mathrm{I}^{2}=76 \%$; table 2 , fig 5), while restriction to those studies with a 10 year lag period showed an association similar to the primary analysis (two studies, 99578 patients; 2.20, 1.72 to $2.81, \mathrm{I}^{2}=0 \%$ ). Pooling of multivariable adjusted hazard ratios showed an increased risk similar to our primary analysis (three studies; adjusted hazard ratio $1.79,95 \%$ confidence interval 1.34 to 2.38 ; $\mathrm{I}^{2}=28 \%$; fig 3). The absolute difference in risk between radiotherapy exposed and unexposed patients ranged between -0.2 and 1.0 cases of rectal cancer per 100 patients (table $\mathrm{C}$, appendix 4).

Unadjusted analysis of studies without restriction to lag period showed no association between radiotherapy and lung cancer (seven studies, 188911 participants; unadjusted odds ratio 1.31, 95\% confidence interval 0.97 to 1.76 ; $I^{2}=84 \%$; fig A, appendix 5). Restriction of analysis to studies with a five year lag period showed marginal significance (three studies, 241298 participants; $1.55,1.00$ to 2.40 ; $\mathrm{I}^{2}=88 \%$; table 2 ), while there was no association in those studies with a 10 year lag period (two studies, 99478 patients; $1.58,0.89$ to $2.83, \mathrm{I}^{2}=76 \%$ ). There was also no association when we pooled multivariable adjusted hazard ratios (two studies; adjusted

\section{Lung cancer}




\begin{tabular}{|c|c|c|c|c|c|c|c|c|}
\hline & \multicolumn{3}{|c|}{ No lag restriction } & \multicolumn{3}{|c|}{5 year lag } & \multicolumn{2}{|c|}{ Adjusted HR } \\
\hline & Studies & No of patients & OR $(95 \% \mathrm{Cl})$ & Studies & No of patients & OR $(95 \% \mathrm{Cl})$ & Studies & HR $(95 \% \mathrm{Cl})$ \\
\hline \multicolumn{9}{|l|}{ Bladder cancer } \\
\hline \multicolumn{9}{|c|}{ Versus no radiotherapy: } \\
\hline Any radiotherapy & 9 & 555873 & $1.39(1.12 \text { to } 1.71)^{\star}$ & 3 & 397416 & $1.30(1.19 \text { to } 1.42)^{\star}$ & 4 & $1.67(1.55 \text { to } 1.80)^{*}$ \\
\hline EBRT & 6 & 186854 & $1.37(1.05 \text { to } 1.77)^{\star}$ & 3 & 397416 & $1.30(1.19 \text { to } 1.42)^{\star}$ & 2 & $1.62(1.20 \text { to } 2.20)^{\star}$ \\
\hline Brachytherapy & 3 & 161889 & $1.25(1.10 \text { to } 1.42)^{\star}$ & 1 & 95826 & 1.45 (0.88 to 2.39$)$ & 2 & 1.04 (0.52 to 2.09$)$ \\
\hline \multicolumn{9}{|l|}{ Versus surgery: } \\
\hline Any radiotherapy & 6 & 692487 & $1.37(1.02 \text { to } 1.84)^{\star}+$ & 2 & 41166 & $1.12(0.85$ to 1.48$)$ & 2 & $1.62(1.38 \text { to } 1.91)^{\star}$ \\
\hline EBRT & 5 & 259521 & $1.39(0.93$ to 2.07$) \dagger$ & 2 & 41166 & $1.12(0.85$ to 1.48$)$ & 2 & $1.63(0.90$ to 2.96$)$ \\
\hline Brachytherapy & 2 & 160001 & $1.26(1.11 \text { to } 1.43)^{\star}$ & NA & NA & - & 1 & 0.66 (0.11 to 3.96$)$ \\
\hline \multicolumn{9}{|l|}{ Colorectal cancer } \\
\hline \multicolumn{9}{|c|}{ Versus no radiotherapy: } \\
\hline Any radiotherapy & 10 & 228965 & $1.68(1.33 \text { to } 2.12)^{\star}$ & 4 & 242878 & $1.94(1.07 \text { to } 3.50)^{\star}+$ & 3 & $1.79(1.34 \text { to } 2.38)^{\star}$ \\
\hline EBRT & 8 & 217396 & $1.78(1.38 \text { to } 2.29)^{\star}$ & 4 & 177061 & $1.93(1.04 \text { to } 3.57)^{\star} \dagger$ & 2 & $1.41(0.78$ to 2.56$) \dagger$ \\
\hline Brachytherapy & 3 & 135716 & 0.99 (0.39 to 2.53)† & 1 & 95826 & 0.15 (0.02 to 1.07$)$ & 1 & 0.96 (0.43 to 2.13) \\
\hline \multicolumn{9}{|l|}{ Versus surgery: } \\
\hline Any radiotherapy & 7 & 332953 & $1.45(1.07 \text { to } 1.96)^{\star}$ & 3 & 127396 & $1.57(0.91$ to 2.70$) \dagger$ & 2 & $1.41(0.78$ to 2.56$) \dagger$ \\
\hline EBRT & 6 & 282014 & $1.52(1.14 \text { to } 2.03)^{\star}$ & 3 & 127396 & $1.57(0.91$ to 2.70$) \dagger$ & 2 & $1.41(0.78$ to 2.56$) \dagger$ \\
\hline Brachytherapy & 2 & 133828 & $1.12(0.19$ to 6.66$) \dagger$ & NA & NA & - & NA & - \\
\hline \multicolumn{9}{|c|}{ Rectal cancer } \\
\hline \multicolumn{9}{|c|}{ Versus no radiotherapy: } \\
\hline Any XRT & 8 & 157239 & $1.62(1.26 \text { to } 2.08)^{\star}$ & 3 & 204064 & 1.68 (0.90 to 3.15$) \dagger$ & 3 & $1.79(1.34 \text { to } 2.38)^{\star}$ \\
\hline EBRT & 6 & 145670 & $1.64(1.21 \text { to } 2.21)^{\star}$ & 3 & 144596 & $1.56(1.31 \text { to } 1.86)^{\star}$ & 2 & $1.74(1.45 \text { to } 2.08)^{\star}$ \\
\hline Brachytherapy & 3 & 135716 & $0.65(0.36$ to 1.19$)$ & 1 & 95826 & $0.28(0.04$ to 1.99$)$ & NA & - \\
\hline \multicolumn{9}{|l|}{ Versus surgery: } \\
\hline Any radiotherapy & 6 & 300488 & 1.30 (0.99 to 1.71$)$ & 2 & 94931 & $1.56(1.26 \text { to } 1.93)^{\star}$ & 2 & $1.74(1.45 \text { to } 2.08)^{*}$ \\
\hline EBRT & 5 & 249549 & $1.38(1.12 \text { to } 1.70)^{*}$ & 2 & 94931 & $1.56(1.26 \text { to } 1.93)^{\star}$ & 2 & $1.74(1.45 \text { to } 2.08)^{\star}$ \\
\hline Brachytherapy & 2 & 133828 & $0.49(0.35$ to 0.67$)$ & NA & NA & - & NA & - \\
\hline \multicolumn{9}{|l|}{ Lung cancer } \\
\hline \multicolumn{9}{|c|}{ Versus no radiotherapy: } \\
\hline Any radiotherapy & 7 & 188911 & $1.31(0.97$ to 1.76$) \dagger$ & 3 & 241498 & $1.55(1.00 \text { to } 2.40)^{\star}+$ & 2 & $1.45(0.70$ to 3.01$) \dagger$ \\
\hline EBRT & 6 & 187023 & $1.33(0.97$ to 1.82$) \dagger$ & 3 & 175681 & $1.60(1.06 \text { to } 2.42)^{\star}+$ & 2 & 1.38 (0.74 to 2.56$)$ \\
\hline Brachytherapy & 3 & 54605 & 0.62 (0.39 to 0.97$)$ & 1 & 95826 & 0.71 (0.43 to 1.19$)$ & 1 & 0.70 (0.22 to 2.23$)$ \\
\hline \multicolumn{9}{|l|}{ Versus surgery: } \\
\hline Any radiotherapy & 5 & 173074 & $1.16(0.81$ to 1.68$) \dagger$ & 2 & 41335 & $2.66(0.52$ to 13.64$) \dagger$ & 2 & $1.45(0.70$ to 3.01$) \dagger$ \\
\hline EBRT & 5 & 172661 & $1.19(0.83$ to 1.71$) \dagger$ & 2 & 41335 & $2.66(0.52$ to 13.64$) \dagger$ & 2 & $1.37(0.71$ to 2.61$)$ \\
\hline Brachytherapy & 1 & 1761 & 0.44 (0.13 to 1.48$)$ & NA & NA & - & 1 & 0.70 (0.22 to 2.23$)$ \\
\hline \multicolumn{9}{|c|}{ Hematological cancers } \\
\hline \multicolumn{9}{|c|}{ Versus no radiotherapy: } \\
\hline Any radiotherapy & 6 & 180032 & $1.33(1.05 \text { to } 1.69)^{\star}$ & 2 & 173232 & 1.30 (0.79 to 2.13$)$ & 1 & 1.64 (0.90 to 2.99$)$ \\
\hline EBRT & 5 & 177740 & $1.36(1.05 \text { to } 1.77)^{\star}$ & 2 & 173232 & 1.30 (0.79 to 2.13$)$ & 1 & 2.09 (0.15 to 29.75$)$ \\
\hline Brachytherapy & 3 & 54605 & $1.08(0.80$ to 1.46$)$ & 1 & 95826 & 0.36 (0.13 to 0.92$)$ & 1 & 0.50 (0.09 to 2.78$)$ \\
\hline \multicolumn{9}{|l|}{ Versus surgery: } \\
\hline Any radiotherapy & 4 & 164195 & 1.16 (0.78 to 1.72$)$ & 1 & 32465 & 1.91 (0.96 to 3.83$)$ & 1 & 1.64 (0.90 to 2.99$)$ \\
\hline EBRT & 4 & 272093 & 1.08 (0.98 to 1.19$)$ & 1 & 32465 & 1.91 (0.96 to 3.83) & 1 & 2.09 (0.15 to 29.75$)$ \\
\hline Brachytherapy & 1 & 1761 & 1.09 (0.39 to 3.01) & NA & NA & - & 1 & 0.50 (0.09 to 2.78$)$ \\
\hline
\end{tabular}

hazard ratio $1.45,95 \%$ confidence interval 0.70 to 3.01 ; $\mathrm{I}^{2}=86 \%$ ). For lung cancers, the absolute difference between patients treated with radiotherapy and those not exposed ranged from -0.9 to 1.1 cancers per 100 patients (table $\mathrm{C}$, appendix 4).

\section{Hematologic cancers}

We found an increased odds of hematologic cancers after radiotherapy in studies without restriction to lag period (six studies, 180032 participants; unadjusted odds ratio $1.33,95 \%$ confidence interval 1.05 to 1.69 ;
$\mathrm{I}^{2}=50 \%$; fig B, appendix 5), but this was not confirmed in studies with a five year lag period (two studies, 172232 patients; $1.30,0.79$ to $2.13 ; I^{2}=57 \%$; table 2 ), a 10 year lag period (one study, 96811 patients; 1.09, 0.94 to 1.27), or multivariable adjusted hazard ratios (one study; adjusted hazard ratio 1.64, 95\% confidence interval 0.90 to 2.99). The absolute difference in risk ranged between -0.6 and 0.2 cases per 100 patients for patients treated with radiotherapy and controls, depending on type of radiotherapy, comparator, and lag period (table $\mathrm{C}$, appendix 4). 


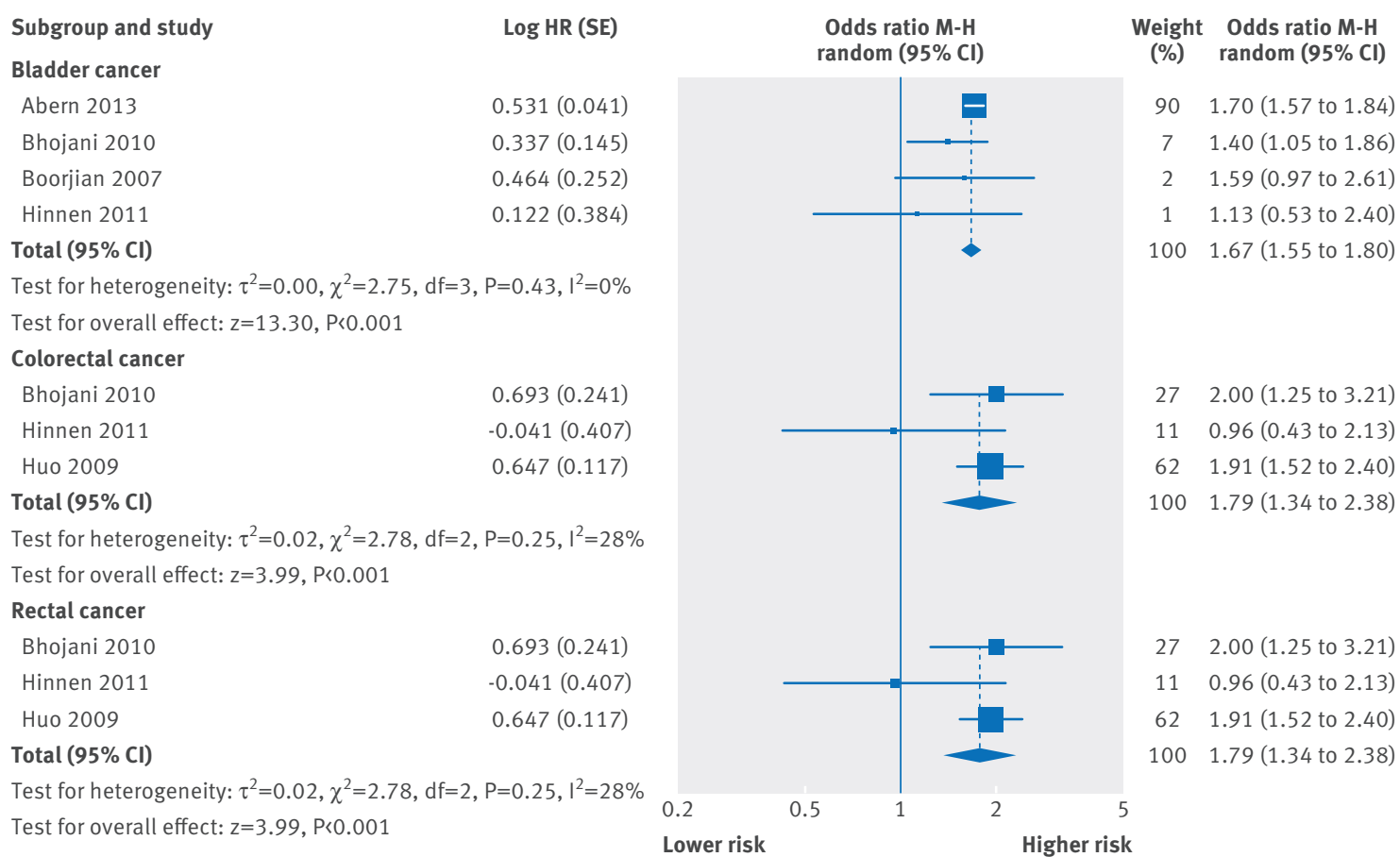

Fig 3 | Risk of cancer after any radiotherapy compared with no radiation in studies reporting adjusted hazard ratios

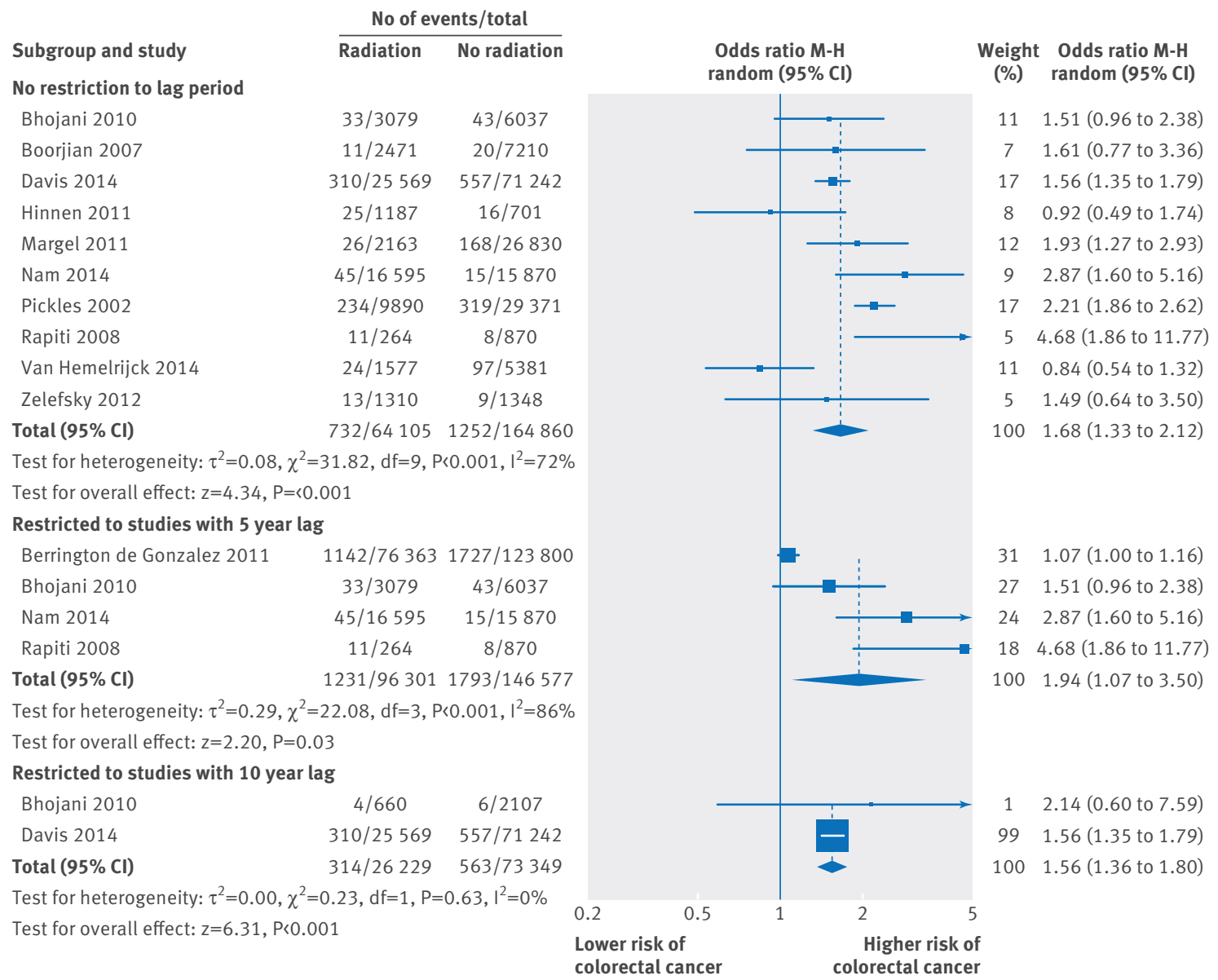

Fig 4 | Risk of colorectal cancer after any radiotherapy compared with no radiation in studies with no restriction to lag period, studies with five year lag period, and studies with 10 year lag period 


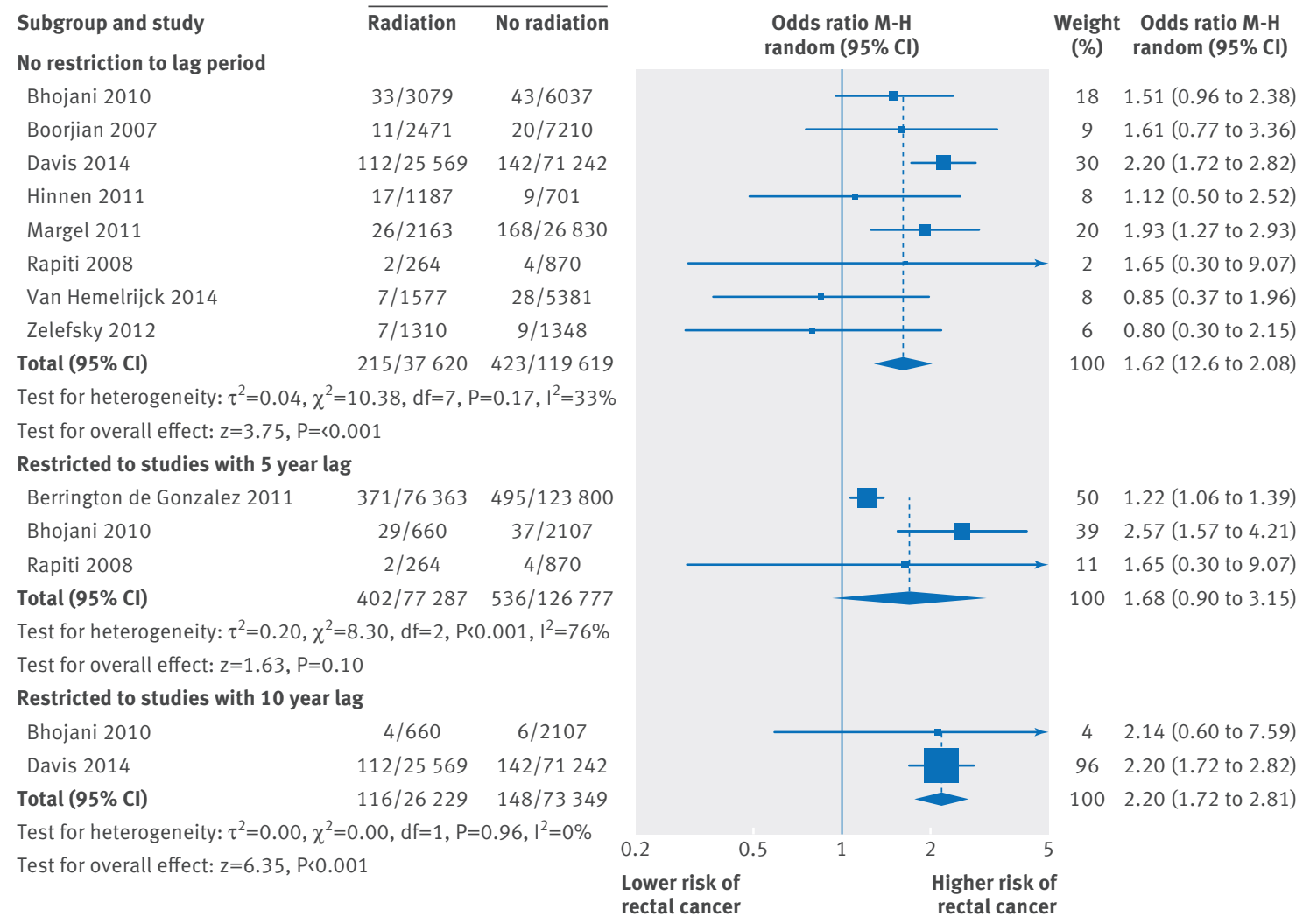

Fig 5 | Risk of rectal cancer after any radiotherapy compared with no radiation in studies with no restriction to lag period, studies with five year lag period, and studies with 10 year lag period

Subgroup analysis and exploration of heterogeneity Studies limited to external beam radiotherapy predominately reported an increased odds of secondary malignancy after radiotherapy, whereas those limited to brachytherapy did not show this association (figs C and D, appendix 5; table 2). We conducted meta-regression using risk of bias score as a continuous variable in a random effects model when more than five studies were included in the meta-analyses. None of the analyses showed a significant effect of risk of bias score (all $\mathrm{P}>0.05$ ) as a covariate on observed associations.

\section{Discussion}

In this comprehensive review and meta-analysis of 21 studies with moderate risk of bias, we identified an association between radiotherapy for prostate cancer and the development of secondary cancers of the bladder, colorectal tract, and rectum, compared with no radiotherapy or surgery. These results were consistent when we pooled multivariable adjusted hazard ratios and restricted analyses to studies using five or 10 year lag periods between treatment and outcome ascertainment. In particular, it is notable in our analysis that odds ratios for bladder and rectal cancer increased with a longer lag time (odds ratio at five year lag $v 10$ year lag: $1.3 v 1.89$ for bladder cancer and $1.68 v 2.2$ for rectal cancer). It is important to note, however, that the differences in absolute risks between cases and controls were low (table 1). In post hoc analyses, the absolute risk difference for patients treated with radiotherapy compared with those not treated with radiotherapy ranged from -0.9 to 1.9 cancers per 100 patients, with differences observed based on type of radiotherapy, comparator group, and lag time duration indicating that absolute risk for these secondary cancers is low.

Given the current understanding that the risk of secondary malignancy related to radiation increases over time, the progressive increase in odds ratio over time seen in our study supports a potential association between radiotherapy and the development of a secondary malignancy of the bladder and rectum. We did not find an association between radiotherapy and lung or hematologic cancers. It must be noted that many of the results were obtained from a small number of studies (between two and 10 in each analyses), and the absolute risk of secondary malignancy remains low. Variation in the crude incidence of secondary cancers is, at least in part, due to differences in follow-up between the included studies.

There was a trend across all analyses for lower odds ratios or hazard ratios in the pooled analysis resulting from studies using surgically treated patients as the control group rather than those using patients unexposed to radiotherapy. This could reflect a selection bias, with lower outcome ascertainment in those patients not treated with a definitive local therapy. Similarly, as patients treated with radiotherapy might experience increased bowel urgency and other recto-anal symptoms, including bleeding, as a result of 
their treatment, ${ }^{3}$ there is a potential for detection bias for colorectal and rectal cancers.

There was significant heterogeneity between studies for many of our outcomes, likely in large part because of the differences in control groups used and specific types of radiation delivered. Some studies used a surgery group 610313738 while others used a "no radiation" group 7304244 and yet others used a "no radiation, no surgery" group. ${ }^{34}$ We sought to diminish the influence of these differences by providing stratified subgroup analyses. Further, within the external beam radiotherapy category, there was heterogeneity in radiotherapy techniques used (two dimensional ${ }^{647}$ and three dimensional $^{6}$ conformational radiotherapy, external beam radiotherapy without further specification, ${ }^{7} 303134373844$ and intensity modulated radiotherapy $\left.{ }^{10}\right)$. Differences in the length of follow-up could contribute further to the heterogeneity. We also explored the role of study risk of bias in the observed heterogeneity. Meta-regression, however, failed to show a significant effect of risk of bias on the observed estimates.

\section{Comparison with other studies}

To our knowledge, there is only one other meta-analysis on this subject in addition to non-systematic reviews of the literature. ${ }^{11} 12131415$ Our review differs from the previous meta-analysis ${ }^{15}$ on this topic, which included only four studies. We identified significantly more studies and even among them we had to select studies from SEER cohort. In addition, most of their analyses relied on a single publication. ${ }^{40}$ Further, they did not assess different radiotherapy techniques separately. Ours is the first attempt to quantify available knowledge on the subject in the most comprehensive, reproducible, and methodologically appropriate fashion.

Secondary primary cancers can arise because of common etiologic factors, including genetic predispositions, or effects related to treatment. Further, there might be issues of diagnostic bias when comparisons are made between treated patients and the general population. Considering that the comparison between patients treated with radiotherapy and those treated with surgery showed similar results to the main analysis, however, our data suggest that secondary cancers are largely because of effects related to treatment.

Several studies have shown differences in the risk of secondary cancer by specific type of radiation treatment. In our analysis, the association between radiotherapy and secondary cancers was much weaker for patients treated with brachytherapy than for those treated with external beam radiotherapy, in keeping with others' work. ${ }^{48}$ Notably, when we assessed crude absolute incidence rates, patients treated with brachytherapy not infrequently had rates of secondary cancer lower than the control group; this likely represents selection of younger and healthier patients for brachytherapy. In a study of a single centre case series compared with the SEER population registry, Huang and colleagues showed no difference in rates of secondary malignancies between those men treated with brachytherapy and radical prostatectomy. ${ }^{32}$ Moon and colleagues found that treatment with brachytherapy was associated with an increased odds of bladder cancer compared with treatment with surgery but that this risk did not apply to other tumor sites. ${ }^{42}$ It can be speculated that brachytherapy could pose a lower risk of secondary malignancy related to radiation than external beam radiotherapy because it delivers much less integral radiation to normal tissues (outside the prostate) than external beam radiotherapy. While we did not examine intensity modulated radiotherapy separately from other types of external beam radiotherapy, it has supplanted conformal external beam radiotherapy in many jurisdictions. ${ }^{49}$ To date, only a single study, by Zelefsky and colleagues, has independently examined the effect of intensity modulated radiotherapy on secondary cancers, and they reported no increased risk. ${ }^{10}$

\section{Strengths and limitations of study}

Major strengths of our review include the comprehensive search, careful selection of studies, critical appraisal of studies, planned subgroup analyses, analyses accounting for time lag in different methods (dichotomous and time incorporated hazards), and inclusion of adjusted estimates for hazard ratio. We must, however, acknowledge the limitations. First, given the number of studies derived from the SEER registry, we had to select a representative study. We used an explicit and transparent method. To ascertain whether study selection affected the results, however, we undertook a sensitivity analysis using the Newcastle-Ottawa risk of bias score as the primary determinant and sample size as the second. This resulted in the selection of a different study in 24 out of 83 comparisons (28.9\%; appendix 6). For these 24 comparisons, the change in selected study resulted in an average change of $-3.5 \%$ in the odds ratio estimates. As a result, the use of different selection criteria resulted in an average change of $-1.02 \%$ when we considered all 83 comparisons. Therefore, we consider the study selection was robust. Second, we lacked important information on confounders and comorbidities and other risk factors associated with cancers other than prostate cancer, which might be higher in patients who are treated with radiotherapy. Of particular note is the lack of information on smoking for the ascertainment of risk of lung and bladder cancer, and obesity, which could predispose patients to colon ${ }^{50}$ and prostate cancer. ${ }^{51}$ This might bias the increased risk attributed to radiotherapy. Third, the small numbers of studies in individual subgroup analyses limited power in our conclusions. Finally, included studies had moderate risk of bias, and there is an ongoing need for high quality and minimally biased studies.

\section{Conclusions and implications for practice and research}

In view of the limited number of studies and limited adjustment for confounders, we identify an important need for future studies assessing the risk of secondary malignancy after radiotherapy for prostate cancer. This can be undertaken either as large prospective cohort 
studies or multinational prospective registries. Implications of our results for clinical practice include use of these results in discussion with patients for decision making. In particular, for patients with a long life expectancy of 20 years or more, the possibility of secondary malignancy related to radiation needs to be included in management discussion. We acknowledge, however, that further studies are required before conclusive implication of the association between radiotherapy and secondary malignancy in these patients.

In conclusion, we identified a possible association between radiotherapy and an increased odds of secondary cancers compared with no radiotherapy or with surgery. We identified consistent evidence of an increased risk of bladder, colorectal, and rectal cancers in men treated with radiotherapy. We did not find consistent evidence for an association between radiotherapy and secondary lung and hematologic cancers. Although there was an increase in risk, the absolute rates of these secondary cancers remain low, particularly compared with other rates of complications associated with treatment for prostate cancer. This information could be helpful in the decision making process regarding such treatment.

We are indebted to Elizabeth Uleryk for her assistance in devising the search strategy. We thank Tom Pickles for providing raw data for inclusion in this analysis.

Contributors: CJDW and RKN designed the study, formulated the clinical question, and identified the PICOS components. CJDW performed the literature search and, with ALM, reviewed the search results for study inclusion. CJDW and ALM designed the data extraction form and extracted the data. CJDW and PSS performed the statistical analyses. CJDW wrote the paper and all other authors critically revised subsequent drafts. All authors approved the final manuscript for submission. CJDW and RKN are guarantors.

Funding: This study was funded by the Ajmera Family chair in urologic oncology awarded to RKN. The funder had no input in the design or conduct of the study, the interpretation of the results, the preparation of the manuscript or the decision to submit for publication. PS is supported by an applied research chair in reproductive and child health services and policy research from the Canadian Institutes of Health Research.

Competing interests: All authors have completed the ICMJE uniform disclosure form at www.icmje.org/coi disclosure.pdf and declare: no support from any organization for the submitted work; no financial relationships with organizations that might have an interest in the submitted work in the previous three years; and no other relationships or activities that could appear to have influenced the submitted work. SH, RTK, SAN, and RKN were authors of one of the included studies.

Ethical approval: This study was approved by the University of Toronto health research ethics board (No 31250). As aggregate data were used, patient consent was not deemed necessary.

Transparency: CJDW and RKN affirm that the manuscript is an honest, accurate, and transparent account of the study being reported; that no important aspects of the study have been omitted; and that any discrepancies from the study as planned have been explained.

Data sharing: Data extracted from published manuscripts is available from the senior author at Robert.Nam@utoronto.ca. Informed consent was not obtained from individual patients but aggregate, previously published data were used in this analysis and all data are fully anonymized.

This is an Open Access article distributed in accordance with the Creative Commons Attribution Non Commercial (CC BY-NC 3.0) license, which permits others to distribute, remix, adapt, build upon this work non-commercially, and license their derivative works on different terms, provided the original work is properly cited and the use is noncommercial. See: http://creativecommons.org/licenses/by-nc/3.0/.

1 Heidenreich A, Bastian PJ, Bellmunt J, et al. European Association of Urology. EAU guidelines on prostate cancer. part 1: screening, diagnosis, and local treatment with curative intent-update 2013. Eur Urol 2014;65:124-37. doi:10.1016/i.eururo.2013.09.046.
2 Potosky AL, Davis WW, Hoffman RM, et al. Five-year outcomes after prostatectomy or radiotherapy for prostate cancer: the prostate cancer outcomes study. / Natl Cancer Inst 2004:96:1358-67. doi:10.1093/jnci/djh259.

3 Resnick MJ, Koyama T, Fan KH, et al. Long-term functional outcomes after treatment for localized prostate cancer. N Engl I Med 2013:368:436-45. doi:10.1056/NEJMoa1209978.

4 Wallis CJ, Cheung P, Herschorn S, et al. Complications following surgery with or without radiotherapy or radiotherapy alone for prostate cancer. Br/Cancer 2015:112:977-82. doi:10.1038/bic.2015.54.

5 Wallis CJ, Herschorn S, Saskin R, et al. Complications after radical prostatectomy or radiotherapy for prostate cancer: results of a population-based, propensity score-matched analysis. Urology 2015;85:621-7. doi:10.1016/j.urology.2014.11.037.

6 Nam RK, Cheung P, Herschorn S, et al. Incidence of complications other than urinary incontinence or erectile dysfunction after radical prostatectomy or radiotherapy for prostate cancer: a populationbased cohort study. Lancet Oncol 2014;15:223-31. doi:10.1016/ S1470-2045(13)70606-5.

7 Berrington de Gonzalez A. Curtis RE, Kry SF, et al. Proportion of second cancers attributable to radiotherapy treatment in adults: a cohort study in the US SEER cancer registries. Lancet Oncol 2011;12:353-60. doi:10.1016/S1470-2045(11)70061-4.

8 Brenner DJ, Curtis RE, Hall EJ, Ron E. Second malignancies in prostate carcinoma patients after radiotherapy compared with surgery. Cancer 2000;88:398-406. doi:10.1002/

(SICI)1097-0142(20000115)88.2<398*.AID-CNCR22>3.0.CO;2-V.

9 Kendal WS, Eapen L, Macrae R, Malone S, Nicholas G. Prostatic irradiation is not associated with any measurable increase in the risk of subsequent rectal cancer [Erratum appears in Int I Radiat Oncol Biol Phys. 2008 Mar 15;70(4):1294-5]. Int I Radiat Oncol Biol Phys 2006;65:661-8. doi:10.1016/j.jirobp.2005.11.013.

10 Zelefsky MJ, Pei X, Teslova T, et al. Secondary cancers after intensity-modulated radiotherapy, brachytherapy and radical prostatectomy for the treatment of prostate cancer: incidence and cause-specific survival outcomes according to the initial treatment intervention. BJU Int 2012;110:1696-701. doi:10.1111/j.1464-410X.2012.11385.x.

11 Müller AC, Ganswindt U, Bamberg M, Belka C. Risk of second malignancies after prostate irradiation?Strahlenther Onkol 2007:183:605-9. doi:10.1007/s00066-007-1786-y.

12 Bostrom PJ, Soloway MS. Secondary cancer after radiotherapy fo prostate cancer: should we be more aware of the risk? Eur Uro 2007:52:973-82. doi:10.1016/i.eururo.2007.07.002.

13 Murray L, Henry A, Hoskin P, Siebert FA, Venselaar J. PROBATE group of GEC ESTRO. Second primary cancers after radiation for prostate cancer: a systematic review of the clinical data and impact of treatment technique. Radiother Oncol 2014:110:213-28. doi:10.1016/j.radonc.2013.12.012

14 Goldstraw MA, Payne H, Kirby RS. What are the risks of second cancer formation after radiotherapy to the prostate?BJU Int 2006;98:489-91. doi:10.1111/j.1464-410X.2006.06288.X.

15 Jin T, Song T, Deng S, Wang K. Radiation-induced secondary malignancy in prostate cancer: a systematic review and metaanalysis. Urol Int 2014:93:279-88. doi:10.1159/000356115.

16 Frieben H. Demonstration eines Cancroid des rechten Handrueckens, das sich nach langdauernder Einwirkung von Roentgenstrahlen entwickelt hatte. Fortschr Geb Rontgenstr 1902:6:106-11.

17 Lehnert BE, Goodwin EH, Deshpande A. Extracellular factor(s) following exposure to alpha particles can cause sister chromatid exchanges in normal human cells. Cancer Res 1997:57:2164-71.9187116.

18 Narayanan PK, Goodwin EH, Lehnert BE. Alpha particles initiate biological production of superoxide anions and hydrogen peroxide in human cells. Cancer Res 1997:57:3963-71.

19 Narayanan PK, LaRue KE, Goodwin EH, Lehnert BE. Alpha particles induce the production of interleukin- 8 by human cells. Radiat Res 1999:152:57-63. doi:10.2307/3580049.

20 Azzam El, de Toledo SM, Gooding T, Little JB. Intercellular communication is involved in the bystander regulation of gene expression in human cells exposed to very low fluences of alpha particles. Radiat Res 1998;150:497-504 doi:10.2307/3579865.

21 Murray EM, Werner D, Greeff EA, Taylor DA. Postradiation sarcomas: 20 cases and a literature review. Int I Radiat Oncol Biol Phys 1999:45:951-61. doi:10.1016/S0360-3016(99)00279-5.

22 Cahan WG, Woodard HQ, Higinbotham NL, Stewart FW, Coley BL. Sarcoma arising in irradiated bone; report of 11 cases. Cancer 1948;1:3-29. doi:10.1002/1097-0142(194805)1:1<3:AID-CNCR2820010103>3.0.CO;2-7.

23 Sale KA, Wallace DI, Girod DA, Tsue TT. Radiation-induced malignancy of the head and neck. Otolaryngol Head Neck Surg 2004;131:643-5. doi:10.1016/j.otohns.2004.05.012

24 Moher D, Liberati A, TetzlaffJ, Altman DG. PRISMA Group. Preferred reporting items for systematic reviews and meta-analyses: the PRISMA statement. J Clin Epidemiol 2009;62:1006-12. doi:10.1016/j. jclinepi.2009.06.005. 
25 Stroup DF, Berlin JA, Morton SC, et al. Meta-analysis of observational studies in epidemiology: a proposal for reporting. Meta-analysis Of Observational Studies in Epidemiology (MOOSE) group. JAMA 2000;283:2008-12. doi:10.1001/jama.283.15.2008.

26 Deeks JJ, Dinnes J, D’Amico R, et al. International Stroke Trial Collaborative Group European Carotid Surgery Trial Collaborative Group. Evaluating non-randomised intervention studies. Health Technol Assess 2003;7:iii-x, 1-173. doi:10.3310/hta7270.

27 Wells GA, Shea B, O'Connell D, et al. The Newcastle-Ottawa Scale (NOS) for assessing the quality of nonrandomized studies in meta-analyses. Secondary The Newcastle-Ottawa Scale (NOS) for assessing the quality of nonrandomized studies in meta-analyses. 2011. http://www.ohri.ca/ programs/clinical epidemiology/oxford.asp.

28 Robins J, Breslow N, Greenland S. Estimators of the Mantel-Haenszel variance consistent in both sparse data and large-strata limiting models. Biometrics 1986;42:311-23. doi:10.2307/2531052.

29 Higgins JP, Thompson SG, Deeks JJ, Altman DG. Measuring inconsistency in meta-analyses. BMJ 2003;327:557-60. doi:10.1136/ bmj.327.7414.557.

30 Pickles T, Phillips N. The risk of second malignancy in men with prostate cancer treated with or without radiation in British Columbia, 1984-2000. Radiother Oncol 2002;65:145-51. doi:10.1016/ S0167-8140(02)00307-9.

31 Margel D, Baniel J, Wasserberg N, Bar-Chana M, Yossepowitch O. Radiation therapy for prostate cancer increases the risk of subsequent rectal cancer. Ann Surg 2011;254:947-50. doi:10.1097/ SLA.0b013e3182382fd5.

32 Huang J, Kestin LL, Ye H, Wallace M, Martinez AA, Vicini FA. Analysis of second malignancies after modern radiotherapy versus prostatectomy for localized prostate cancer. Radiother Oncol 2011:98:81-6. doi:10.1016/j.radonc.2010.09.012.

33 Singh A, Kinoshita Y, Rovito PM Jr, et al. Higher than expected association of clinical prostate and bladder cancers. J Urol 2008:179(Suppl):S2-5. doi:10.1016/j.juro.2008.03.130.

34 Abdel-Wahab M, Reis IM, Hamilton K. Second primary cancer after radiotherapy for prostate cancer--a seer analysis of brachytherapy versus external beam radiotherapy. Int I Radiat Oncol Biol Phys 2008;72:58-68. doi:10.1016/j.ijrobp.2007.12.043.

35 Abern MR, Dude AM, Tsivian M, Coogan CL. The characteristics of bladder cancer after radiotherapy for prostate cancer. Urol Oncol 2013·31:1628-34. doi:10.1016/j.urolonc.2012.04.006.

36 Baxter NN, Tepper JE, Durham SB, Rothenberger DA, Virnig BA. Increased risk of rectal cancer after prostate radiation: a populationbased study. Gastroenterology 2005;128:819-24. doi:10.1053/j. gastro.2004.12.038

37 Bhojani N, Capitanio U, Suardi N, et al. The rate of secondary malignancies after radical prostatectomy versus external beam radiation therapy for localized prostate cancer: a population-based study on 17,845 patients. Int J Radiat Oncol Biol Phys 2010;76:342-8. doi:10.1016/j.jirobp.2009.02.011.

38 Booriian S, Cowan JE, Konety BR, et al. Cancer of the Prostate Strategic Urologic Research Endeavor Investigators. Bladder cancer incidence and risk factors in men with prostate cancer: results from Cancer of the Prostate Strategic Urologic Research Endeavor. J Urol 2007;177:883-7, discussion 887-8. doi:10.1016/j.juro.2006.10.071.
39 Davis EJ, Beebe-Dimmer JL, Yee CL, Cooney KA. Risk of second primary tumors in men diagnosed with prostate cancer: a population-based cohort study. Cancer 2014;120:2735-41. doi:10.1002/cncr.28769.

40 Hinnen KA, Schaapveld M, van Vulpen M, et al. Prostate brachytherapy and second primary cancer risk: a competitive risk analysis. J Clin Oncol 2011;29:4510-5. doi:10.1200/JCO.2011.35.0991.

41 Huo D, Hetzel JT, Roy H, Rubin DT. Association of colorectal cancer and prostate cancer and impact of radiation therapy. Cancer Epidemiol Biomarkers Prev 2009;18:1979-85. doi:10.1158/1055-9965. EPI-09-0241.

42 Moon K, Stukenborg GJ, Keim J, Theodorescu D. Cancer incidence after localized therapy for prostate cancer. Cancer 2006;107:991-8. doi:10.1002/cncr.22083.

43 Nieder AM, Porter MP, Soloway MS. Radiation therapy for prostate cancer increases subsequent risk of bladder and rectal cancer: a population based cohort study. J Urol 2008;180:2005-9, discussion 2009-10. doi:10.1016/i.juro.2008.07.038.

44 Rapiti E, Fioretta G, Verkooijen HM, et al. Increased risk of colon cancer after external radiation therapy for prostate cancer. Int J Cancer 2008;123:1141-5. doi:10.1002/ijc.23601.

45 Singh AK, Mashtare TL, McCloskey SA, Seixas-Mikelus SA, Kim HL, May $\mathrm{KS}$. Increasing age and treatment modality are predictors for subsequent diagnosis of bladder cancer following prostate cancer diagnosis. Int J Radiat Oncol Biol Phys 2010;78:1086-94. doi:10.1016/j.jirobp.2009.09.055

46 Van Hemelrijck M, Feller A, Gormo H, et al. Incidence of second malignancies for prostate cancer in the canton of Zurich, 1980-2010. Eur J Cancer 2014;50:S230-31doi:10.1016/S0959-8049(14)50838-6.

47 Overholser L, Garrington T, Greffe B, et al. Managing late and long term effects of childhood cancer treatment. / Gen Intern Med 2010;25:S527.

48 Takam R, Bezak E, Yeoh EE. Risk of second primary cancer following prostate cancer radiotherapy: DVH analysis using the competitive risk model. Phys Med Biol 2009:54:611-25. doi:10.1088/0031-9155/54/3/009.

49 Nguyen PL, GuX, Lipsitz SR, et al. Cost implications of the rapid adoption of newer technologies for treating prostate cancer. J Clin Oncol 2011;29:1517-24. doi:10.1200/JCO.2010.31.1217.

50 Frezza EE, Wachtel MS, Chiriva-Internati M. Influence of obesity on the risk of developing colon cancer. Gut 2006;55:285-91. doi:10.1136/ gut.2005.073163.

51 Engeland A, Tretli S, Biørge T. Height, body mass index, and prostate cancer: a follow-up of 950000 Norwegian men. Br J Cancer 2003;89:1237-42. doi:10.1038/sj.bjc.6601206.

Appendix 1: Selection of representative SEER study for each outcome

Appendix 2: Literature search strategy Appendix 3: Studies included for each outcome Appendix 4: Supplementary tables A-C Appendix 5: Supplementary figures A-D Appendix 6: Sensitivity analysis 